\title{
The Puzzle of Partial Resource Use by a Parasitoid Wasp
}

\section{Montovan, Kathryn J.}

2015-04

Montovan , K J , Couchoux , C , Jones , L E , Reeve , H K \& van Nouhuys , S 2015 , ' The

Puzzle of Partial Resource Use by a Parasitoid Wasp ' , American Naturalist , vol. 185 , no. 4 , pp. 538-550 . https://doi.org/10.1086/680036

http://hdl.handle.net/10138/154638

https://doi.org/10.1086/680036

publishedVersion

Downloaded from Helda, University of Helsinki institutional repository.

This is an electronic reprint of the original article.

This reprint may differ from the original in pagination and typographic detail.

Please cite the original version. 


\section{CHICAGO JOURNALS}

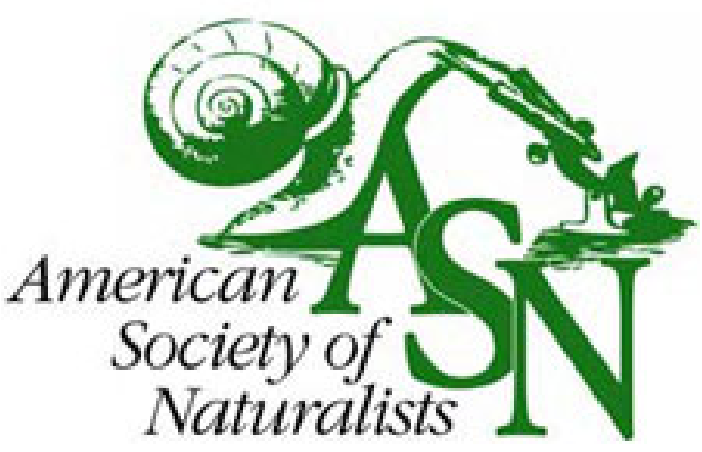

The University of Chicago

The Puzzle of Partial Resource Use by a Parasitoid Wasp

Author(s): Kathryn J. Montovan, Christelle Couchoux, Laura E. Jones, H. Kern Reeve and

Saskya van Nouhuys,

Source: The American Naturalist, (-Not available-), p. 000

Published by: The University of Chicago Press for The American Society of Naturalists

Stable URL: http://www.jstor.org/stable/10.1086/680036

Accessed: 06/03/2015 14:17

Your use of the JSTOR archive indicates your acceptance of the Terms \& Conditions of Use, available at

http://www.jstor.org/page/info/about/policies/terms.jsp

JSTOR is a not-for-profit service that helps scholars, researchers, and students discover, use, and build upon a wide range of content in a trusted digital archive. We use information technology and tools to increase productivity and facilitate new forms of scholarship. For more information about JSTOR, please contact support@ jstor.org. 


\title{
The Puzzle of Partial Resource Use by a Parasitoid Wasp
}

\author{
Kathryn J. Montovan, ${ }^{1, \star}$ Christelle Couchoux, ${ }^{2, \dagger}$ Laura E. Jones, ${ }^{1,3}$ H. Kern Reeve, ${ }^{4}$ and \\ Saskya van Nouhuys ${ }^{2,3, \neq}$
}

1. Center for Applied Math, Cornell University, Ithaca, New York 14853; 2. Department of Biosciences, P.O. Box 65 (Viikinkaari 1), University of Helsinki, 00014 Helsinki, Finland; 3. Department of Ecology and Evolutionary Biology, Cornell University, Ithaca, New York 14853; 4. Department of Neurobiology and Behavior, Cornell University, Ithaca, New York 14853

Submitted March 27, 2014; Accepted November 14, 2014; Electronically published February 27, 2015

Online enhancement: appendix. Dryad data: http://dx.doi.org/10.5061/dryad.h08r6.

AвSTRACT: When there is conspicuous underexploitation of a limited resource, it is worth asking, what mechanisms allow presumably valuable resources to be left unused? Evolutionary biologists have generated a wide variety of hypotheses to explain this, ranging from interdemic group selection to selfishly prudent individual restraint. We consider a situation in which, despite high intraspecific competition, individuals leave most of a key resource unexploited. The parasitic wasp that does this finds virtually all host egg clusters in landscape but parasitizes only about a third of the eggs in each and then leaves a deterrent mark around the cluster. We first test-and reject - a series of system-specific simple constraints that might limit full host exploitation, such as asynchronous maturation of host eggs. We then consider classical hypotheses for the evolution of restraint Prudent predation and bet-hedging fail as explanations because the wasp lives as a large, well-mixed population. Additionally, we find no individual benefits to the parasitoid of developing in a sparsely parasitized host nest. However, an optimal foraging model, including empirically measured costs of superparasitism and hyperparasitism, can explain through individual selection both the consistently low rate of parasitism and deterrent marking.

Keywords: competition, Hyposoter horticola, Melitaea cinxia, optimal foraging theory, predator-prey interactions, population dynamics.

\section{Introduction}

Under strong resource competition, a limiting resource is predicted to become entirely depleted. However, because of population-level responses to resource availability, this does not generally occur, especially in persistent predatorprey or host-parasite interactions (Abrams 2000; Hassell 2000). Here we consider an animal that, at the individual rather than the population level, consistently does not deplete an apparently available resource. We examine the

\footnotetext{
* Present address: Bennington College, Bennington, Vermont 05201.

${ }^{\dagger}$ Present address: School of Life Sciences, University of Sussex, Brighton BN1 9QG, United Kingdom.

* Corresponding author; e-mail: saskya@cornell.edu.

Am. Nat. 2015. Vol. 185, pp. 000-000. (C) 2015 by The University of Chicago 0003-0147/2015/18504-55383\$15.00. All rights reserved.

DOI: $10.1086 / 680036$
}

consistently low resource use by a parasitoid, Hyposoter horticola (Hymenoptera: Ichneumonidae). This wasp parasitizes the butterfly Melitaea cinxia (Lepidoptera: Nymphalidae) in Åland, Finland. It locates host egg clusters in the landscape during the weeks before they are ready to be parasitized (van Nouhuys and Ehrnsten 2004) and monitors the egg clusters, using memorized visual landmarks (van Nouhuys and Kaartinen 2008). The wasp parasitizes a portion of nearly every host egg cluster in the landscape, with the great majority of the parasitism in each cluster due to one female (C. Couchoux, P. Seppä, and S. van Nouhuys, unpublished manuscript A). This behavior leads to a uniform rate of parasitism, largely independent of scale of observation and host density (van Nouhuys and Hanski 2002). Here we address why individual $H$. horticola, which are clearly resource limited, parasitize just a fraction of the hosts available to them, mark the clusters they parasitize, and are deterred by the markings left by others.

We use a combination of empirical and theoretical methods to assess nine mechanisms that could potentially lead to a rate of parasitism that is systematically low. Aspects of this topic have been addressed for parasitoid wasps empirically (Cronin and Strong 1993a, 1993b; Bouskila et al. 1995) and theoretically (Ayal and Green 1993; Rosenheim and Mangel 1994; Driessen and Bernstein 1999). Here we present a broad, integrated analysis in one empirical research system. The interaction between M. cinxia and H. horticola is especially suitable for this study because it is simple, with a parasitoid supported by a single host species. Additionally, the population and behavioral ecology for both the host (Hanski 2011; Ojanen et al. 2013) and the parasitoid (van Nouhuys and Hanski 2002; van Nouhuys and Kaartinen 2008) have been well studied on a large spatial scale.

\section{Research System}

The host butterfly Melitaea cinxia has a Eurasian distribution. In the Åland Islands of Finland, it lives as a metapopulation in a network of 4,000 small meadows over an 
area of $3,500 \mathrm{~km}^{2}$. The meadows are surveyed annually, with 300-500 of them occupied by the butterfly in any given year (Ojanen et al. 2013). Individual butterflies lay clusters of eggs on the host plants (Plantago lanceolata and Veronica spicata: Plantaginaceae) in June (Kuussaari et al. 2004). The eggs take 2-3 weeks to develop; then, shortly before hatching, essentially all of the egg clusters are parasitized by Hyposoter horticola (van Nouhuys and Hanski 2002; van Nouhuys and Ehrnsten 2004). The wasp is solitary and mobile, foraging on a larger scale than does the host (Kankare et al. 2005). It has no hosts other than $M$. cinxia (Shaw et al. 2009). Typically females spend 20-60 min parasitizing a host egg cluster (Couchoux and van Nouhuys 2014), ovipositing in about a third of the eggs (field conditions: $N=43, \bar{x}=0.31[ \pm 0.12$ SD]; laboratory: $N=10$, $\bar{x}=0.32[ \pm 0.07 \mathrm{SD}]$; comparison of field to laboratory conditions using Welch's $t$-test: $t_{22.7}=0.279, P=.393$; van Nouhuys and Ehrnsten 2004). Afterward, the wasp marks the leaves around the egg cluster, which deters conspecificsand perhaps itself - from parasitizing the remaining hosts (C. Couchoux, P. Seppä, and S. van Nouhuys, unpublished manuscript A).

\section{Plausible Explanations for Partial Resource Use}

\section{Physical Limitations to Parasitism}

Multiple physical and physiological limitations might restrict the wasp's ability to parasitize an entire host egg cluster. These are as follows: (1) wasp egg limitation-an individual may have few eggs available at a given time, or it may have only enough eggs to parasitize a small fraction of hosts encountered over a lifetime (Bouskila et al. 1995; Mangel 2006; Rosenheim 2011); (2) host egg cluster architecture-not all of the host eggs in a cluster may be accessible to the parasitoid ovipositor (Weseloh 1972; Hondo et al. 1995); (3) host egg immunological defensea fraction of hosts may kill the wasp eggs through immune defense (Lavine and Strand 2002); and (4) ephemeral resource availability - if host eggs develop asynchronously within a cluster, only a fraction may be susceptible while the wasp is present (Briggs and Latto 1996). Alternatively, if the eggs mature synchronously, while they are susceptible the wasp may have enough time to parasitize only some of them (Nakamichi et al. 2008). Although each physical/physiological constraint could explain fractional parasitism, none would explain why a wasp applies or respects the deterrent markings of the host egg clusters.

\section{Behavioral Limitations to Parasitism}

We next consider classical ecological and evolutionary scenarios that have been used to explain behavioral restraint in other resource-exploiter systems.
Prudent Predation (Parasitism). Restrained harvesting strategies increase resource availability for future generations. This would benefit only the specific individuals practicing restraint if the species lived in small populations with limited mixing (Smith 1964; Slobodkin 1974). Prudence has been used to explain reduced predation in some predatorprey interactions (Wilson 1978). However, the Melitaea cinxia-Hyposoter horticola system does not meet the requirements for this. While the host butterfly does live as networks of local populations in a fragmented landscape (Hanski 2011), individual wasps are dispersive (van Nouhuys and Hanski 2002), with overlapping ranges and only very weak geographic genetic structure (Kankare et al. 2005). Thus, there is no opportunity for the evolution of prudence.

Bet-Hedging. Another possible mechanism for partial resource exploitation is distribution of reproductive effort. This can reduce variability in the expected number of surviving offspring. For instance, in temporally varying environments an organism may decrease year-to-year variation by spreading reproductive effort over multiple time periods (Gillespie 1977; Rajon et al. 2014). While conditions do vary between years for $H$. horticola (van Nouhuys et al. 2003; Hanski and Meyke 2005), an individual can reproduce only in a single season, so temporal risk spreading between years is not possible.

In spatially structured heterogeneous environments, individuals in very small populations may increase fitness by spreading offspring over the landscape. This would decrease the probability of extinction of a particular genotype. But in large, well-mixed populations, there is no long-term selective benefit to such reduced variance of individual success (Gillespie 1977; Hopper 1999; Mangel 2006). Melitaea cinxia larval nest mortality varies spatially (van Nouhuys et al. 2003; Hanski and Meyke 2005). As noted, however, the population of $H$. horticola wasps is large and well mixed, so bet-hedging individuals would not predominate. Because we rule out both prudence and bet-hedging, neither are considered further.

Cooperative Benefits. Cooperatively feeding gregarious caterpillars such as $M$. cinxia rely on each other for survival (Kuussaari et al. 2004; Costa 2006). If parasitized caterpillars perform poorly, then the performance of highly parasitized groups would be low, decreasing individual parasitoid fitness, perhaps below the threshold necessary for the survival of the parasitoids in a host nest. Selection due to this would favor restraint in oviposition by parasitoid females.

Optimal Foraging, Including Mortality due to Superparasitism and Avoidance of Hyperparasitism. The final hypotheses for evolution of behavioral restraint are based on 
a classical optimal foraging model, in which an individual is predicted to stop using a resource patch once the marginal benefit turns negative. For instance, the marginal value theorem predicts that individuals balance time or energy spent at a given resource patch with that spent traveling to a new resource patch (Charnov 1976). As a forager depletes a resource patch, it experiences diminished returns. At some point, the expected gain of leaving to find a new patch will exceed the reward of remaining, even taking into account transit time, and the forager is predicted to leave. There are many examples of consumers leaving resource patches because of diminished returns (Sih 1980), and this has been modeled for parasitoid wasps (Wajnberg 2006; Eliassen et al. 2009). We first consider a basic optimal foraging model that assumes that $H$. horticola experiences diminishing returns with increased time at a host egg cluster (resource patch). The longer it stays, the more likely it is to encounter host eggs that it has already parasitized. Superparasitism is costly to solitary parasitoids (Rosenheim and Mangel 1994). We measure the actual amount of superparasitism that occurs and compare the outcome of the model when one parasitoid successfully develops within a superparasitized host and when superparasitism causes mortality of all parasitoid eggs in a host. We then consider the risk of hyperparasitism (parasitism of the parasitoid), which is another potentially densitydependent factor leading to diminishing returns. To do this realistically, we use field data to measure the association between rate of hyperparasitism and rate of parasitism and determine how it changes the outcome of the optimal foraging model.

\section{Methods and Results}

In the following sections, we present both the experimental tests of and the results for each potential mechanism of partial parasitism, excluding prudent parasitism and bethedging, which were eliminated above. We start by considering the four simple biological explanations.

\section{Species-Specific Biological Constraint: Wasp Egg Limitation}

Egg-limited parasitoids do not produce sufficient eggs to parasitize all of the hosts they can encounter in a patch or during a lifetime. They must thus choose which hosts to use (Jervis et al. 2001; Rosenheim 2011). Melitaea cinxia egg clusters contain only about 150 eggs (Saastamoinen 2007). Couchoux and van Nouhuys (2014) found that female Hyposoter horticola contain $\bar{x}=550$ ( \pm 173 SD) mature eggs in their oviducts under laboratory conditions. Because H. horticola is synovigenic, it is likely to mature new eggs to replace those that are used (Jervis et al. 2001). A large-scale study of the genetic structure of $H$. horticola in Åland (C. Couchoux, P. Seppä, and S. van Nouhuys, unpublished manuscript B) showed that, on average, a successful mother parasitizes about four egg clusters, two of which survive the winter (van Nouhuys et al. 2003). So, although evolutionary pressures may have brought $H$. horticola to this point, at present in Åland the wasp is not strongly egg limited. Most individuals successfully parasitize significantly fewer hosts than they have eggs, and egg limitation cannot dictate the average foraging behavior. Additionally, if host egg clusters differed in quality and wasps were choosey, then the rate of parasitism would be predicted to vary greatly from cluster to cluster - which it does not, even with respect to egg cluster size (van Nouhuys and Ehrnsten 2004; Couchoux and van Nouhuys 2014).

\section{Species-Specific Biological Constraint: Host Egg Cluster Architecture}

Melitaea cinxia lay eggs in mounds. For some insect species, the inner eggs in mounds are inaccessible to the parasitoid ovipositor (Weseloh 1972; Hondo et al. 1995), with up to half of the eggs in the protected inner layers (Friedlander 1985). To find out whether H. horticola is restricted to the outer eggs, we compared parasitism rates of inner and outer layers of host egg clusters. Eleven egg clusters were exposed to parasitism by H. horticola in the laboratory (see appendix section "General Experimental Procedures" for methods; appendix is available online). Seven wasps were used, with three each parasitizing a single cluster and the other four each parasitizing two clusters. Immediately after parasitism, the outer layer of eggs was separated from the rest of the cluster. Both categories were then dissected to determine the fractions parasitized. The inner and outer eggs were parasitized equally (outer eggs: $\bar{x}=0.43[ \pm 0.16 \mathrm{SD}]$; inner eggs: $\bar{x}=0.48[ \pm 0.22 \mathrm{SD}]$; paired $t$-test: $\left.t_{8}=1.1929, P=.2604\right)$, indicating that mounding does not protect the inner host eggs from parasitism. The data are available in the Dryad Digital Repository: http://dx.doi.org/10.5061/dryad.h08r6 (Montovan et al. 2014).

\section{Species-Specific Biological Constraint: Host Egg Immunological Defense}

Insects can defend themselves against endoparasitoids by encapsulating or otherwise preventing development of parasitoid eggs or larvae (Lavine and Strand 2002). For instance, $M$. cinxia caterpillars encapsulate up to half the larvae of the parasitoid Cotesia melitaearum (Hymenoptera: Braconidae; van Nouhuys et al. 2012). If the majority of $M$. cinxia were resistant to parasitism by $H$. horticola, then the low rate of successful parasitism would be 
explained by host immunity. However, encapsulation of $H$. horticola would have to occur early in host development (before the host hatches from the egg), which is both unlikely and costly (Schmid-Hempel 2005; Ardia et al. 2012). Furthermore, there is no evidence of encapsulation. For instance, no dead parasitoid eggs were found in M. cinxia caterpillars dissected within hours of hatching, such as those used in this study. These early-dissected caterpillars also did not have a higher incidence of parasitism $(N=64$, $\bar{x}=0.30[ \pm 0.13 \mathrm{SD}])$ than in previous studies in which the caterpillars were dissected later in development (34\%; van Nouhuys and Ehrnsten 2004) or on adult emergence (36\%; van Nouhuys and Punju 2010).

Nonetheless, we approached this idea comparatively. On the assumption that resistance to parasitism is costly, hosts from places where the parasitoid occurs may have evolved resistance, whereas without the parasitoid there would be no or low resistance (Kraaijeveld et al. 2002). In the laboratory, we compared the rate of successful parasitism of M. cinxia from Åland with that of $M$. cinxia from Morocco, which lacks $H$. horticola. The only known parasitoid of M. cinxia caterpillars in Morocco is C. melitaearum (S. van Nouhuys, personal observation), which parasitizes older caterpillars (van Nouhuys and Punju 2010). In this experiment, 11 egg clusters from butterflies from Åland and 15 from Morocco were parasitized in the laboratory, each by a different by $H$. horticola individual from Åland. For methods, see appendix section "General Experimental Procedures." Eggs from both origins were parasitized at the same frequency $\left(28 \% \pm 17 \% \mathrm{SD}\right.$; Welch's $t$-test: $t_{19.46}=-0.0047$, $P=.9963$; table 1), indicating no local resistance in Åland.

\section{Species-Specific Biological Constraint: Ephemeral Resource Availability}

Temporal asynchrony of the adult parasitoid with the susceptible stage of the host can create a short opportunity for parasitism (Briggs and Latto 1996). The window of time

Table 1: Summary of results from the Åland, Estonia, and Morocco parasitism comparison studies (appendix section "General Experimental Procedures")

\begin{tabular}{llll}
\hline \multicolumn{2}{c}{ Origin } & & \\
\cline { 1 - 2 } Host & Wasp & $n$ & $\mu_{\mathrm{p}} \pm \sigma_{\mathrm{p}}(\%)$ \\
\hline Åland & Åland & 11 & $28 \pm 21$ \\
Åland & Estonia & 14 & $35 \pm 18$ \\
Estonia & Åland & 10 & $43 \pm 17$ \\
Estonia & Estonia & 14 & $38 \pm 18$ \\
Morocco & Alland & 15 & $28 \pm 18$ \\
\hline
\end{tabular}

Note: Variables are as follows: $n$ is the number of host clusters, $\mu_{\mathrm{p}}$ is the mean fraction parasitized, and $\sigma_{\mathrm{p}}$ is the standard deviation of the fractions parasitized. The data are available in the Dryad Digital Repository: http:// dx.doi.org/10.5061/dryad.h08r6 (Montovan et al. 2014).
$H$. horticola has to parasitize eggs within a host cluster depends on the length of time individual eggs are susceptible and on the degree of synchrony of hatching within a cluster.

Melitaea cinxia eggs start out bright yellow. After 1215 days, the eggs change to a creamy color, develop dark specks, and turn gray; then, just before the caterpillar hatches, the top of the egg becomes nearly black. Wasps do not probe clusters of bright yellow eggs, and once the caterpillars start to hatch the wasps are no longer attracted to the cluster (Castelo et al. 2010). To determine the association between the developmental stage of the host eggs and the rate of parasitism, we observed which visible phases of egg development were parasitized by the wasp. Thirtyfour host egg clusters of different stages of maturity (starting with all of the eggs creamy) were exposed to parasitism in the laboratory (see appendix section "General Experimental Procedures"). Each of 11 wasps was used several times (two to seven). Immediately after parasitism, the eggs within each cluster were separated into four categories: creamy, speckled, gray topped, and black topped. On hatching, the caterpillars were dissected to determine which were parasitized.

We analyzed the association between parasitism and egg maturity category using logistic regression in JMP (JMP 2012). The explanatory variable was egg maturity (creamy, speckled, gray topped, and black topped). Egg cluster ID and wasp ID were included in the model to account for intracluster or intraindividual correlation in responses. The number of replicates was too unbalanced to include observation number for each wasp in the analysis. Previous experience is known to affect wasp behavior generally (Vet et al. 1990); however, it is unlikely to influence the outcome here because, in similar experiments using $H$. horticola, no change in rate of parasitism was detected after the first oviposition experience (Castelo et al. 2010). We found that parasitism differed among wasps $\left(\chi_{10}^{2}=68.1924, P<.0001\right)$ and among host egg clusters $\left(\chi_{8}^{2}=55.3932, P<.0001\right)$ but did not differ significantly between the four egg maturity classes $\left(\chi_{3}^{2}=4.1523, P=.2455\right)$. Summed over the egg clusters (each containing only some of the maturity classes), the rate of parasitism was 0.15 for creamy, 0.27 for speckled, 0.27 for gray topped, and 0.30 for black topped. The data are available in the Dryad Digital Repository: http://dx.doi.org /10.5061/dryad.h08r6 (Montovan et al. 2014).

To determine the amount of time a cluster contains susceptible eggs, we took hourly photographs of $10 \mathrm{egg}$ clusters over the last 1-5 days of development and calculated the amount of time that at least $95 \%$ of the eggs in the cluster were in one of the last three visible stages of development (speckled, gray topped, and black topped). The minimum interval of susceptibility for these 10 egg clusters was approximately $28 \mathrm{~h}$, and the mean was $\bar{x}=64$ ( $\pm 38 \mathrm{SD}$ ). To demonstrate the pattern of development 
within an egg cluster, we videotaped an egg cluster for more than $80 \mathrm{~h}$, from when the first eggs became susceptible until hatching (fig. 1). In this case, the susceptible period lasted at least $40 \mathrm{~h}$, which is much greater than the $20 \mathrm{~min}$ to $1 \mathrm{~h}$ spent at a cluster. Because a wasp can probe approximately one egg per minute (computed in appendix section "Probing Efficiency $b$ "), $H$. horticola is not constrained by rate or synchrony of egg development in a cluster.

In sum, $H$. horticola has enough mature eggs in its ovaries and oviducts to parasitize multiple whole clusters. All of the eggs in the cluster are physically accessible to the ovipositor, and the eggs are susceptible to parasitism for much longer than a wasp attends to the cluster. Although some other physical or physiological factor could keep a parasitoid from parasitizing more hosts, we have tested those that seem plausible.

\section{Cooperative Benefits of Unparasitized Hosts}

Melitaea cinxia caterpillars live in gregarious family groups until their final instar (Kuussaari et al. 2004). The fitness of a cooperative group depends on the performance of each individual. Thus, if parasitized caterpillars contribute less to the group than unparasitized caterpillars, increasing the group rate of parasitism would decrease the performance of parasitoids developing within the hosts. We determined the effect that rate of parasitism has on parasitoid performance by manipulating the fraction of caterpillars parasitized per nest in a replicated laboratory experiment, measuring the rate of development, weight at diapause, size at pupation of the host and parasitoid, and production of silk by the hosts at diapause. For methods, including the statistical models used, see appendix section "Measuring the Fitness Cost of Living in a Highly Parasitized Host Nest."

At the prediapause stage, the rate of parasitism among nests ranged from $12 \%$ to $65 \%(\bar{x}=36 \%$ [ $\pm 15 \% \mathrm{SD}])$ among the 30 caterpillar groups. Parasitized caterpillars developed from second instar to diapause in $\bar{x}=29.28$ days $( \pm 2.82 \mathrm{SD})$. The development time differed among replicate groups but was unrelated to the rate of parasitism in a group $\left(F_{1,24.72}=0.0092, P=.9242\right)$. The prediapause development time of unparasitized caterpillars was about the same and also did not differ with rate of parasitism of the group $\left(F_{1,24.72}=0.0110, P=.9172\right)$. At diapause, parasitized caterpillars weighed $\bar{x}=9.47 \mathrm{mg}( \pm 5.93 \mathrm{SD})$, which did not vary with rate of parasitism $\left(F_{1,36.88}=1.9877\right.$, $P=.1670)$. Very few caterpillars died in this experiment, so mortality was not analyzed. On molting to diapause, the caterpillars produced silk to make a winter nest. Groups with a high rate of parasitism produced the most silk $\left(F_{4,34}=\right.$ $8.9052, P<.0001)$. This effect was due to the especially high production of silk by the most parasitized groups (post hoc test: $\left.F_{1,34}=32.51, P<.0001\right)$.

For the postdiapause caterpillars, the rate of parasitism ranged from $5 \%$ to $61 \%(\bar{x}=32 \%[ \pm 13 \% \mathrm{SD}])$. There was nearly $30 \%$ mortality due to a viral infection that came late in the experiment. The mortality of parasitized caterpillars due to the virus differed among replicate groups (maximum likelihood $\left.\chi_{36}^{2}=70.6167, P=.0005\right)$ but was unrelated to rate of parasitism $\left(\chi_{1}^{2}=0.00013, P=.9971\right)$. Parasitized caterpillars developed from diapause to pupation in $\bar{x}=27.55$ days $( \pm 2.79 \mathrm{SD})$, which increased marginally with rate of parasitism $\left(F_{1,30.5}=3.5813, P=.0680\right)$. There was no association between development rate of

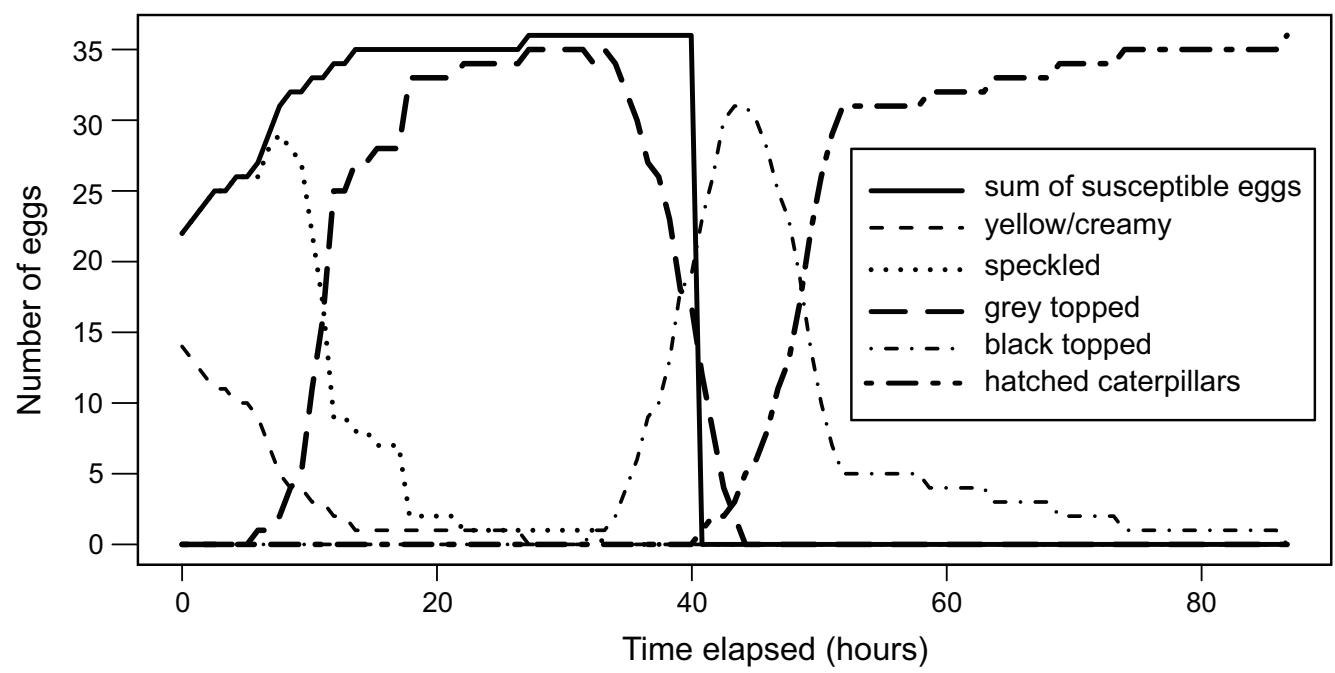

Figure 1: Temporal pattern of host egg development in one Melitaea cinxia egg cluster. Lines show the number of host eggs in each developmental stage. The black solid line (sum of the susceptible egg stages) falls abruptly as the first caterpillar emerges, after which the wasp will no longer parasitize any eggs in the cluster. The susceptible time for the egg cluster is at least $40 \mathrm{~h}$. 
unparasitized caterpillars and parasitism rate $\left(F_{1,21.36}=\right.$ $1.1915, P=.2872)$. Parasitoid pupae weighed $\bar{x}=48.96 \mathrm{mg}$ $( \pm 12.08 \mathrm{SD})$, and their weight did not vary with rate of parasitism. Butterfly pupae weighed $\bar{x}=177.13 \mathrm{mg}( \pm 28.18$ $\mathrm{SD})$. In contrast to the parasitoid, butterfly pupal weight decreased with increasing parasitism rate $\left(F_{1,26.94}=5.5352\right.$, $P=.0262$ ).

On the basis of these experiments, we see no great benefit for $H$. horticola of being in a nest with low parasitism. It is unlikely that the 1-day (3\%) increase in development rate between the lowest and the highest rate of parasitism could have a large negative effect over a 1-year life cycle. The positive association between parasitism and silk production warrants further study because silk is positively associated with winter nest quality, which is important for overwintering success of the host (Kuussaari et al. 2004) and, hence, the wasp. Because of the experimental design, we could measure the effects of abnormally low parasitism but not extremely high parasitism. Thus, our treatments safely span the normal range (van Nouhuys and Ehrnsten 2004) but do not address the possible negative effects of very high parasitism (greater than twice the normal rate).

\section{Optimal Foraging}

Optimal foraging models are used to predict how an animal should partition limited time between procuring resources and using them (Charnov and Skinner 1984, 1985). Hyposoter horticola has a limited time to forage for host egg clusters distributed in a landscape and parasitize them, so an optimal foraging model seems appropriate. At a host egg cluster, $H$. horticola probes host eggs unsystematically, making haphazard passes across the cluster (K. J. Montovan, personal observation). Because only one $H$. horticola larva can develop within each caterpillar, foraging efficiency diminishes over time as the wasp increasingly encounters previously parasitized hosts (fig. 2). The wasp is predicted to ultimately leave. Other within-patch density-dependent factors, such as host mortality due to superparasitism and hyperparasitism, would further decrease the marginal benefit from continuing to parasitize a host cluster.

Observed Superparasitism Rates. For solitary parasitoid species, superparasitism results in mortality of parasitoids and sometimes hosts. Some species are able to avoid superparasitism, while others are not (Godfray et al. 1994). To determine the potential cost of superparasitism, we assessed its frequency. Host egg clusters were exposed to parasitism naturally in the field $(N=5)$ and in the laboratory $(N=25)$, and the caterpillars were dissected on hatching to count the number of parasitoid eggs. These dissections showed that although only one wasp reaches maturity within a given host (van Nouhuys and Punju 2010), superparasitism occasionally occurs (fig. 3). We used these data (Dryad Digital Re-

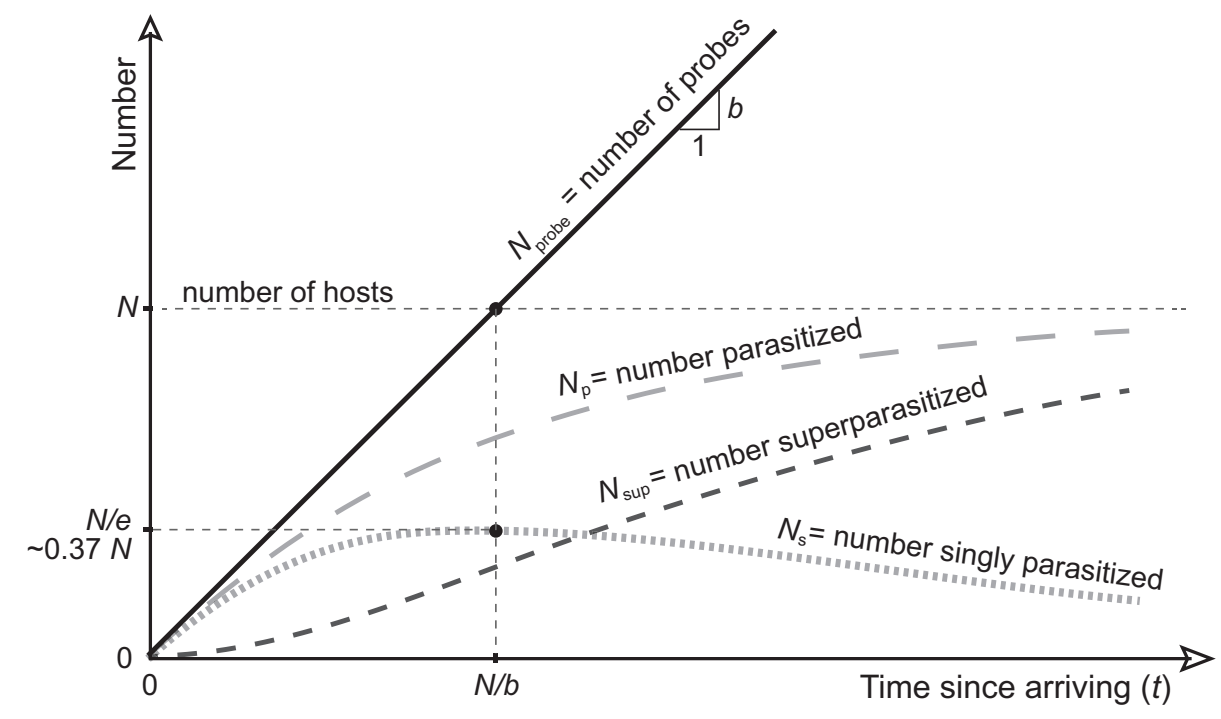

Figure 2: Schematic model of parasitism with random probing and no avoidance of superparasitism. Lines represent the number of times a wasp probes eggs in the cluster (solid line), the total number of hosts parasitized at least once (long-dashed line), the number of superparasitized hosts (medium-dashed line), and the number of singly parasitized hosts (short-dashed line). Calculations are shown in appendix section "Modeling How Reliably Wasps Avoid Superparasitism." $N$ represents the total number of eggs in the cluster. On the singly parasitized curve, the point $(N / b, N / e)$ is at the maximum of the $N_{\mathrm{s}}$ curve; N/e shows the maximum number of singly parasitized hosts the wasp can make. For partial superparasitism avoidance (as done by Hyposoter horticola), the curve would lie between $N$ and $N_{\mathrm{p}}$, tending toward 0 at very long times $(t)$. 


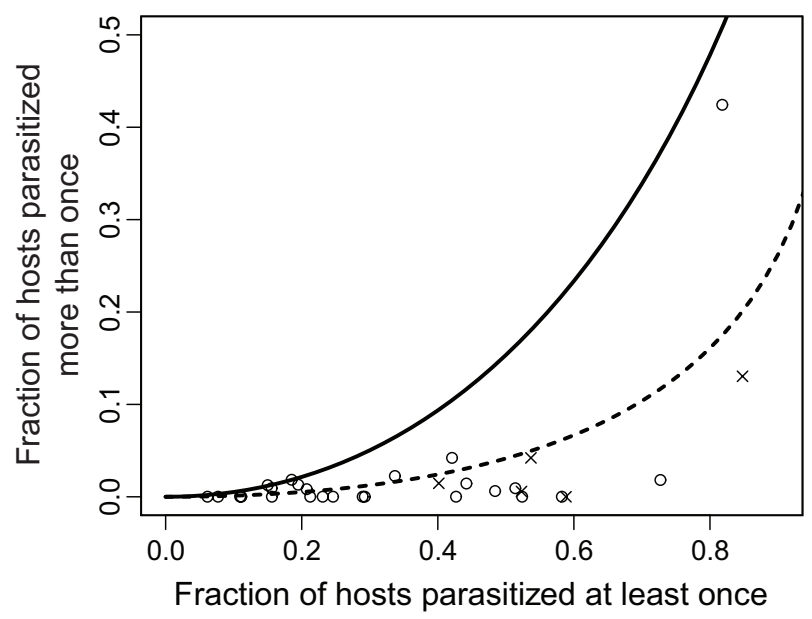

Figure 3: Frequency of superparasitism. The fraction of caterpillars parasitized is plotted against the fraction containing multiple Hyposoter horticola eggs, parasitized in the laboratory (circles) and field (crosses). The solid line shows the expected fraction of hosts containing multiple parasitoid eggs if wasps choose eggs randomly without avoiding superparasitism. The dotted line shows the best-fit line for the data (77\% avoidance of superparasitism). Calculations are shown in appendix section "Modeling How Reliably Wasps Avoid Superparasitism," where the fitted parameter $(z)$ is the expected probability of detecting a previous parasitism and not laying an egg (here $z=0.767, \mathrm{SE}=0.036, P<.001$ ). The data are available in the Dryad Digital Repository: http://dx.doi.org/10.5061/dryad .h08r6 (Montovan et al. 2014).

pository: http://dx.doi.org/10.5061/dryad.h08r6; Montovan et al. 2014) to estimate the probability of superparasitism (see appendix section "Modeling How Reliably Wasps Avoid Superparasitism") and found that when a wasp encounters a previously parasitized egg, it successfully avoids parasitizing that egg again $77 \%$ of the time (dotted line in fig. 3 ). The strong avoidance of superparasitism suggests that it is costly, due to either the risk associated with superparasitism or (if it had not been excluded as a possibility) egg limitation.

Optimal Foraging Modeling. The expected number of host eggs in a cluster parasitized singly or multiple times is

$$
N_{\mathrm{p}} \approx N\left(1-e^{-b t / N}\right)
$$

where $N$ is the total number of hosts in a cluster, $b$ is the probing rate (taken from laboratory data; see appendix section "Probing Efficiency $b$ "), and $t$ is the time spent probing the cluster.

The parasitism frequency function (eq. [1]) predicts the number of parasitoid offspring in a cluster. It assumes that each probe by the wasp is independent and random (see appendix section "Modeling How Reliably Wasps Avoid Superparasitism"), that only one wasp parasitizes each cluster (C. Couchoux, P. Seppä, and S. van Nouhuys, unpub- lished manuscript A), and that if an egg is superparasitized, exactly one wasp larva will survive (eq. [1]). We were not able to experimentally determine whether one offspring survives or all offspring die in superparasitized hosts, so we also used a model in which superparasitism kills both wasps so the number of parasitoid offspring is the expected number of host eggs parasitized exactly once:

$$
N_{1} \approx \frac{N e^{-b t / N}}{z}\left(e^{b t z / N}-1\right),
$$

where $z$ is the probability of avoiding superparasitism, calculated in appendix section "Modeling How Reliably Wasps Avoid Superparasitism." The average fitness is then defined as the parasitism rate (similar to the net energy intake functions in Charnov 1976), which is the number of eggs parasitized in each cluster $\left(N_{\mathrm{p}}\right.$ or $\left.N_{1}\right)$ divided by the time the wasp spends "searching for" $\left(t_{\mathrm{s}}\right)$ and parasitizing $(t)$ a cluster. The search time $t_{\mathrm{s}}$, in its simplest form, is the time it takes a wasp to reach the next available host egg cluster. Natural selection acts on $t$, the time spent probing each cluster. The fitness functions (generically $w(t)$ ), representing parasitism efficiency without mortality of multiply parasitized eggs $\left(w_{1}(t)\right)$ and assuming complete mortality of multiply parasitized eggs $\left(w_{2}(t)\right)$, are

$$
\begin{aligned}
& w_{1}(t)=\frac{N_{\mathrm{p}}}{t_{\mathrm{s}}+t} \approx \frac{N\left(1-e^{-b t / N}\right)}{t_{\mathrm{s}}+t}, \\
& w_{2}(t)=\frac{N_{1}}{t_{\mathrm{s}}+t} \approx \frac{N e^{-b t / N}\left(e^{b t z / N}-1\right)}{z\left(t_{\mathrm{s}}+t\right)} .
\end{aligned}
$$

To maximize the fitness $(w(t))$ with respect to time spent parasitizing $(t)$, we differentiated $w(t)$ and solved for $t$ when $\mathrm{d} w(t) / \mathrm{d} t=0$ and $\mathrm{d}^{2} w(t) / \mathrm{d} t^{2}<0$, finding the optimal value of $t$ numerically and then using this value in the expressions for $N_{\mathrm{p}}$ or $N_{1}$.

Figure 4 shows the resulting optimal fraction parasitized for both parasitism functions. Over realistic ranges of egg cluster size ( $N$; fig. $4 A)$ and probing rate $(b$; fig. $4 B$ ), the optimal fraction parasitized is fairly insensitive to changes in the number of eggs or probing rate. Because the expected time it takes a wasp to reach another host egg cluster $\left(t_{\mathrm{s}}\right)$ is unknown, we tested the model over a large range of searching times. For intermediate values of $t_{\mathrm{s}}$ $\left(0.25<t_{\mathrm{s}}<1 \mathrm{~h}\right)$ and realistic values of $N$ and $b$, both models predict an optimal fraction parasitized close to the observed $30 \%$ (fig. $4 \mathrm{C}$ ). Including mortality due to superparasitism (bold dashed line) lowers the optimal parasitism rates and creates a larger range of search times $\left(t_{\mathrm{s}}\right)$ for which we would expect to see the wasp parasitize close to $30 \%$ of hosts. Thus, optimal foraging with diminishing returns due to random probing (with or without superparasitism as entirely lethal) can explain the observed 


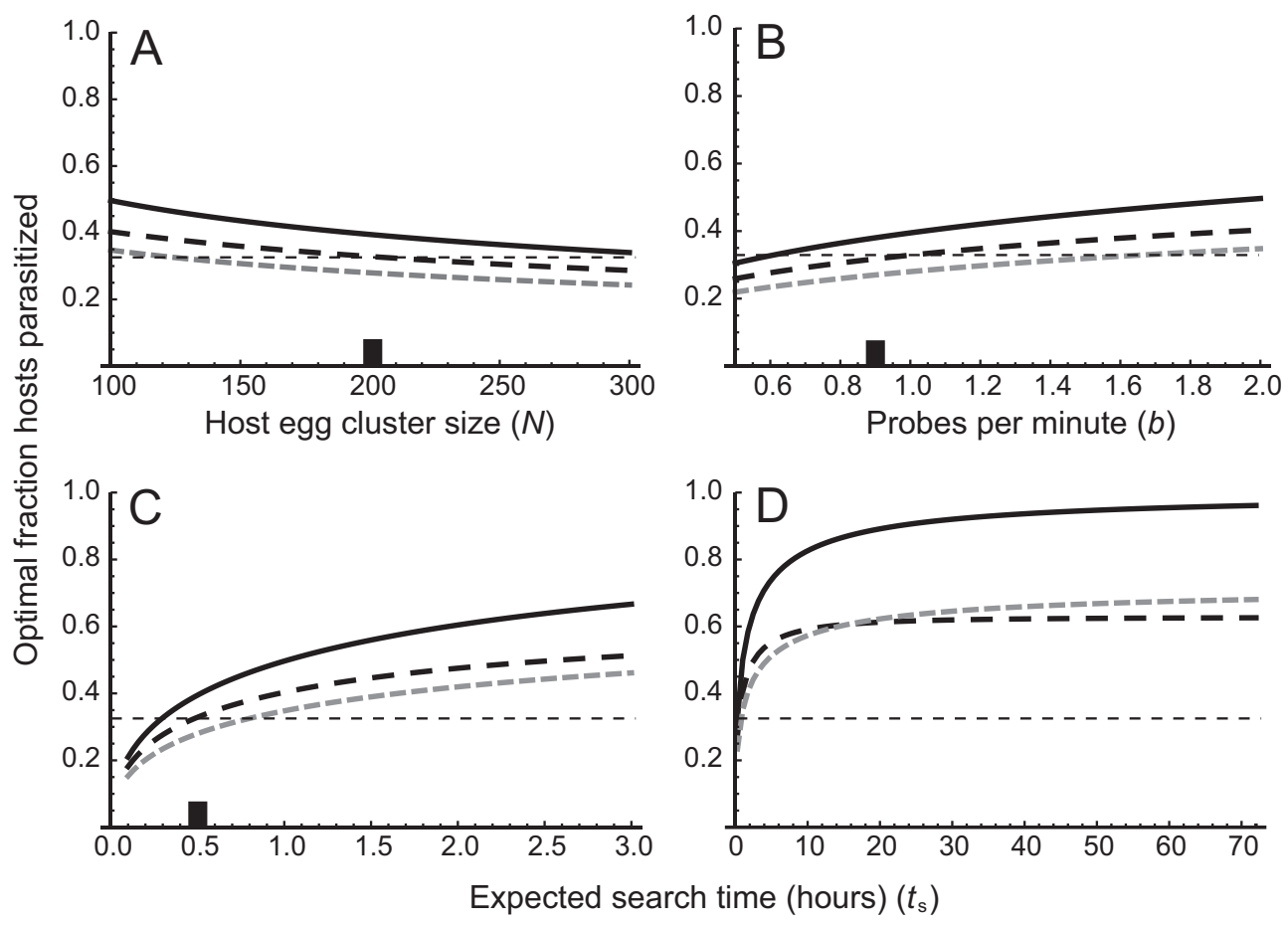

Figure 4: Optimal foraging predictions for the parasitism rate. Three cases are compared with the observed mean parasitism rate in the field (thin dashed lines): parasitized hosts produce one wasp (model $w_{1}(t)$; eq. [3]; bold solid lines); assuming that parasitoids in multiply parasitized hosts die (model $w_{2}(t)$; eq. [4]; bold dashed lines); and including the cost of hyperparasitism (model $w_{3}(t)$; eq. [6]; dashed gray lines). For each panel, one variable was varied and the rest were held constant (black rectangles) at $N=200$ eggs (Kuussaari et al. 2004$) ; b=0.9$ (appendix section "Probing Efficiency $b$ "), $t_{\mathrm{s}}=0.5 \mathrm{~h}$ (best guess for transit time). Predictions depend on $N(A), b(B)$, and $t_{\mathrm{s}}$, the search time to the next egg cluster at short $(C)$ and long $(D)$ timescales.

parasitism frequencies if the wasp's searching time is intermediate (about a half hour). A search time of a few minutes leads to a very low rate of parasitism, less than $30 \%$. A long search time (more than $2 \mathrm{~h}$; fig. $4 \mathrm{D}$ ) leads to a parasitism rate above $60 \%$.

Avoiding Hyperparasitism. Parasitoids might also behave so as to reduce the risk of mortality of their offspring, imposed by natural enemies (Ayal and Green 1993). The hyperparasitoid Mesochorus stigmaticus (Hymenoptera: Ichnuemonidae) parasitizes $H$. horticola larvae within $M$. cinxia caterpillars. Multiple $M$. stigmaticus females visit a caterpillar nest over several weeks during the summer, spending from minutes to hours there (Reichgelt 2007). Most host egg clusters are hyperparasitized, at a rate of up to $50 \%$. We empirically determined the association between rate of hyperparasitism and rate of parasitism by $H$. horticola and included this in the optimal foraging model. We also compared parasitism frequencies of $H$. horticola from populations with (Åland) and without (Estonia) M. stigmaticus to see whether the H. horticola from Åland have evolved low parasitism frequency in the presence of the hyperparasitoid.
We measured the hyperparasitism frequency over a range of parasitism frequencies using two data sets. The first was 16 field-collected naturally parasitized and hyperparasitized nests. To extend the range of parasitism rate and standardize for nest size and location, we also constructed nests of $60 \mathrm{M}$. cinxia caterpillars, as in the experiment on cooperative benefits (see appendix section "Measuring the Fitness Cost of Living in a Highly Parasitized Host Nest"). We left nests containing naturally parasitized caterpillars undiluted $(N=12)$, diluted $1: 1$ $(N=10)$, and diluted $2: 1(N=11)$; this resulted in $10 \%-$ $60 \%$ parasitism. We then placed the randomized nests in 10 different habitat patches to be naturally hyperparasitized by $M$. stigmaticus. After 3 weeks in July, when $M$. stigmaticus was active, we retrieved the nests and reared the caterpillars. The following spring we recorded the numbers that produced adult butterflies, $H$. horticola or $M$. stigmaticus. The data are available in the Dryad Digital Repository: http://dx.doi.org/10.5061/dryad.h08r6 (Montovan et al. 2014).

We used logistic regression to estimate the relationship between the fraction of the cluster that was parasitized by $H$. horticola and the probability that those parasitoid lar- 
vae were hyperparasitized. The dependent variable measured whether each parasitized host egg was also hyperparasitized by $M$. stigmaticus, where $p=N_{\mathrm{p}} / N$ is the fraction of parasitized host caterpillars (fig. $5 A$ ). The independent variable was the fraction of the cluster that was parasitized by $H$. horticola. The intercept was estimated as $-1.86(\mathrm{SE}=0.27, P<.001)$, and the coefficient associated with the parasitism frequency was 2.7 ( $\mathrm{SE}=0.5, P<$ .001 ). Combining these estimates, the probability that a parasitized egg was hyperparasitized is thus fit as

$$
h(p)=1 /\left(1+e^{1.86-2.7 p}\right) .
$$

Under this pressure of hyperparasitism, the expected number of parasitoid offspring per cluster $\left(N_{\mathrm{ps}}\right)$ is

$$
N_{\mathrm{ps}}=N \cdot p(1-h(p))
$$

Figure $5 B$ shows $N_{\mathrm{ps}} / N$. This leads to a new version of the optimal foraging model with the following fitness function (using eq. [1]):

$$
w_{3}(t)=\frac{N_{\mathrm{ps}}}{t_{\mathrm{s}}+t}=w_{1}(t)\left(1-\frac{1}{1+e^{-1.86-2.7\left(1-e^{-b t / N}\right)}}\right) .
$$

The same numerical methods described for the basic optimal foraging model were used to determine the optimum parasitism frequencies (dashed gray lines in fig. 4)
The predicted optimal fraction parasitized is similar to that in which all parasitoid larvae in superparasitized hosts die (bold dashed lines in fig. 4).

As a second approach to the potential effects of hyperparasitism on the rate of parasitism, we compared $H$. horticola from Åland with those from Estonia $(250 \mathrm{~km}$ by sea from Åland), which is free of hyperparasitism (S. van Nouhuys, personal observation). If $H$. horticola has evolved to parasitize at a low frequency to avoid a density-dependent hyperparasitism in Åland, then we might expect individuals from Estonia not to exhibit such restraint and to parasitize a larger fraction of the hosts in a cluster.

In a fully crossed experiment, $H$. horticola from Åland and Estonia were offered $M$. cinxia eggs from Åland and Estonia (see appendix section "General Experimental Procedures"). We compared the frequency of parasitism using a generalized linear model in $\mathrm{R}$ ( $\mathrm{R}$ Development Core Team 2011). Parasitism rate was modeled as a function of egg cluster origin (Åland, Estonia), wasp origin (Åland, Estonia), and the interaction between wasp and egg origin. See table 1 for the number of replicates and results for each treatment. On average, $36 \%$ of the eggs in a cluster were parasitized. There was no significant difference between wasp $\left(t_{1,47}=0.891, P=.377\right)$ or egg $\left(t_{1,47}=1.763, P=\right.$ $.085)$ origins, and there was no interaction between them $\left(t_{3,45}=1.093, P=.280\right)$. Thus, despite evidence from the optimal foraging model that the wasp is predicted to decrease the rate of parasitism to avoid hyperparasitism, this experiment does not support the hypothesis that $H$. horticola
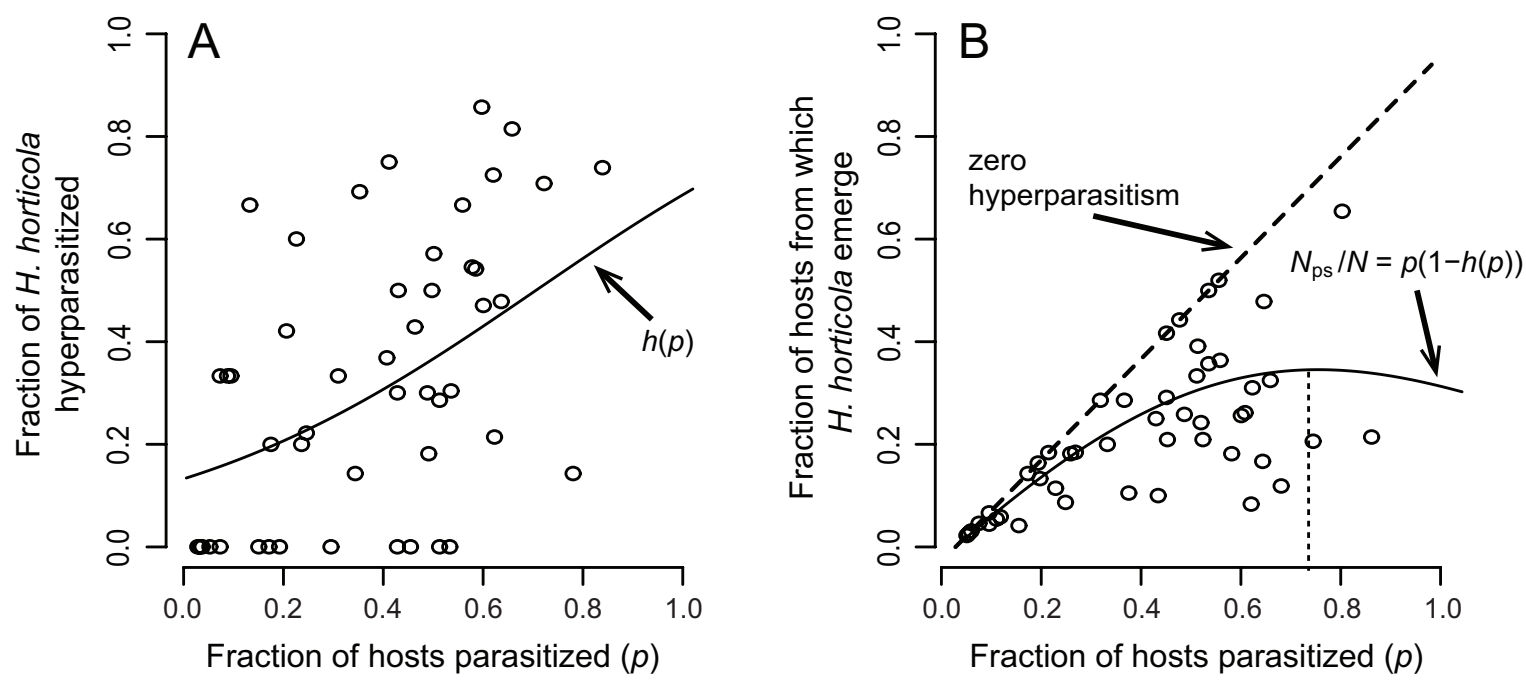

Figure 5: Benefits of parasitism under hyperparasitism pressure. Shown is the relationship between the fraction of hosts parasitized by Hyposoter horticola and the fraction of those hyperparasitized $(A)$ and the fraction of hosts from which $H$. horticola eventually emerge $(B)$. The dashed line $(y=x)$ represents the expected fraction of hosts that produce adult $H$. horticola in the absence of hyperparasitism. The solid line shows the best fit curve from logistic regression $\left(h(p)=1 /\left(1+e^{1.86-2.7 p}\right)\right.$; eq. [5]). Note that, taking hyperparasitism into account, there is no gain for $H$. horticola to parasitize at a rate more than 0.7 (dashed vertical line in $B$ ). The data are available in the Dryad Digital Repository: http://dx.doi.org/10.5061/dryad.h08r6 (Montovan et al. 2014). 
from Åland have evolved restraint because of pressure from the hyperparasitoid.

\section{Discussion}

Hyposoter horticola forages in a competitive environment in which virtually all host egg clusters are found, and many are monitored by multiple females until they become susceptible to parasitism. Yet only about a third of each host egg cluster is parasitized, each primarily by one female. Here we examined explanations for why the wasp does not further exploit its host, using experiments, comparative studies, and mathematical modeling.

\section{Simple Biological and Physiological Constraints}

Host egg cluster architecture, synchrony, or asynchrony in the development rate of host eggs within a cluster and the early immune response of the host do not appear to limit the wasp. An individual female also contains more eggs than needed to parasitize a single host egg cluster, and because it does not parasitize many egg clusters in its life and can probably make new eggs as they are used, a wasp, on average, is unlikely to be egg limited over a lifetime. Because $H$. horticola has specialized biology and an extremely narrow host range, it is unsurprising that the wasp is not limited in these ways. We would only expect simple biological limitations to be effective constraints if, instead, the parasitoid were poorly adapted to the host.

\section{Behavioral Restraint: Prudent Parasitism, Risk Spreading, and Cooperative Benefits}

When individuals are physically and physiologically able to further exploit a resource but do not, they are exhibiting behavioral restraint. We rejected prudence and risk aversion as explanations because in Alland H. horticola has a large population that is well mixed across the landscape (Kankare et al. 2005). We also found that wasps do not benefit from developing in host nests with low parasitism: although Melitaea cinxia caterpillars live gregariously and rely on cooperative behavior to survive, the fraction parasitized did not significantly affect the prediapause or postdiapause developmental rates, weight, or survival of the wasps. The lack of a measurable fitness cost of parasitism is unsurprising because a parasitoid larva stays extremely small (first instar) throughout most of the development of the host caterpillar and then grows rapidly, consuming the entire host just before it would have pupated (van Nouhuys and Punju 2010).

\section{Behavioral Restraint: Optimal Foraging}

Unlike the previous scenarios, optimal foraging shows promise as an explanation for partial resource use by $H$. horticola. In the most basic model, efficiency at a host egg cluster decreases solely because the wasp probes randomly and only one larva can develop within each host. As the wasp spends more time at the cluster, it finds fewer and fewer unparasitized eggs and thus benefits from leaving the cluster to find another (fig. 2). Such a model has been used to predict the very low rate of parasitism by Anagrus delicatus, a tiny parasitoid of leaf hoppers (Rosenheim and Mangel 1994) that is unable to distinguish between parasitized and unparasitized host eggs (Cronin and Strong 1993a). Although $H$. horticola can avoid superparasitism with $77 \%$ accuracy, it still experiences diminished returns as the rate of parasitism increases. If superparasitized hosts die, then there are eventually even negative returns as parasitism increases. The key general principle is that extreme underexploitation of resources can occur when exploitation progressively reduces the value of the remaining resources in the patch (Charnov 1976).

Any other factors that add cost with increased parasitism - or time at a cluster - affect predictions of the optimal foraging model. We hypothesized that time at a cluster would be reduced due to density-dependent hyperparasitism (Ayal and Green 1993). This is a compelling multitrophic behavioral explanation (Sullivan and Völkl 1999) that does indeed reduce the optimal rate of parasitism. In our models, risk of both superparasitism and hyperparasitism similarly reduced the optimal rate of parasitism with respect to search time, egg cluster size $(N)$, and probing rate ( $b$; fig. 4). Interestingly, despite this cost there is no evidence that wasps from Åland have evolved a lower parasitism rate than wasps from Estonia, where there are no hyperparasitoids.

The optimal foraging model is sensitive to the search time between clusters $\left(t_{\mathrm{s}}\right)$ and predicts that the rate of parasitism is about $30 \%$ when $t_{\mathrm{s}}$ is about a half hour. On the one hand, we know that $H$. horticola successfully parasitizes only a few clusters in a few weeks (C. Couchoux, P. Seppä, S. van Nouhuys, unpublished manuscript B), so $t_{\mathrm{s}}=30 \mathrm{~min}$ is too short. On the other hand, the wasp knows the locations of the clusters ahead of time, and most travel times are only seconds to minutes (van Nouhuys and Ehrnsten 2004; van Nouhuys and Kaartinen 2008), so $t_{\mathrm{s}}=30 \mathrm{~min}$ is too long. For the optimal foraging (timebudget) model to be applicable to this research system, we have to interpret $t_{\mathrm{s}}$ differently, taking into account activities associated with the strong intraspecific competition among foraging females (van Nouhuys and Ehrnsten 2004; Hardy et al. 2013; Couchoux and van Nouhuys 2014). For $H$. horticola, a successful individual is one who is a strong competitor, devoting a large fraction of its time to monitoring and attending host egg clusters that are not yet ready to be parasitized. Any time the wasp spends parasitizing is time not spent competing, thus reducing future gain. Under 
this scenario, $t_{\mathrm{s}}$ represents the time that must be invested to protect, on average, one future egg cluster.

\section{Behavioral Restraint: The Role of Deterrent Marking}

After $H$. horticola has finished parasitizing, it applies a chemical mark on the leaves around the cluster (C. Couchoux, P. Seppä, S. van Nouhuys, unpublished manuscript A). Other parasitoid species are known to mark individual hosts or clusters and modify their search behavior in response their own marking or the marks of conspecifics (Höller and Hörmann 1993; Bernstein and Driessen 1996). None of the simple biological explanations for consistently low parasitism could provide explanations for deterrent marking by $H$. horticola. Nor could prudence, bet-hedging, or cooperative benefits. The optimal foraging model does. If a wasp leaves when additional parasitism would reduce its expected fitness (due to risk of self-superparasitism or hyperparasitism), it may benefit by leaving a mark to assist itself in avoiding further parasitizing the same cluster (Mangel 1989; Varaldi et al. 2005). A second wasp that approaches the same cluster would also maximize its fitness by leaving to search for an unused cluster. This makes it intuitive that a wasp might both mark and respect a deterrent mark left by another wasp (Roitberg and Mangel 1988; Hoffmeister and Roitberg 1997). As an aside, just as it is adaptive for some solitary parasitoids to engage in superparasitism (van Alphen and Visser 1990; Speirs et al. 1991), surely some individuals would benefit from further parasitizing a previously used cluster. We might then expect that the effectiveness of th $\rightarrow$ deterrent mark decreases with increasing competition for host egg clusters.

\section{Conclusion}

Any time an individual exercises extreme restraint in tht use of an apparently available yet limiting resource, we wonder why. This article illustrates that while there are multiple potential explanations for the evolution ancmaintenance of low exploitation of available resources, many turn out to be implausible. None of the simple physical or physiological mechanisms examined explain the pattern. Two well-known behavioral mechanisms, prudence and bet-hedging, are also not relevant because the wasp population is large and well mixed. We also found nc $\rightarrow$ indication that individuals benefit from being in a sparsely parasitized cooperatively feeding host group. The surviving candidate explanation is that Hyposoter horticola practices partial parasitism and deterrent marking as a way to forage optimally for hosts and avoid superparasitism, with the avoidance of density-dependent hyperparasitism as a further incentive for restraint. The plausibility of the optimal foraging hypothesis depends on a $t_{\mathrm{s}}$ of about a half hour, which in this system should be considered not as search time but as the time not spent parasitizing or competing for hosts. In this study, we found - as has been found in many circumstances by others-that individual selection is a stronger force than bet-hedging or prudence through group selection and should be carefully disentangled when thinking about the evolutionary causes of any surprisingly low resource use.

\section{Acknowledgments}

We thank D. Muru for help in the group fitness study; L. Salvaudon for help in the egg cluster architecture study; M. Brunfeldt, S. Ikonen, T. Lahtinen, and E. Metsovouri for laboratory help; A. Ruina for help with figures and appendix section "Modeling How Reliably Wasps Avoid Superparasitism"; and S. P. Ellner for advice on fitting multinomial data in appendix section "Modeling How Reliably Wasps Avoid Superparasitism.” T. Collet, T. Day, X. Fauvergue, I. Hanski, M. Mangel, A. Ruina, K. Woods, and two anonymous reviewers made helpful comments on the manuscript. Funding came from Academy of Finland grants 250444,213547 , and 125553 to S.v.N. and a travel grant to K.J.M. from the Department of Ecology and Evolutionary Biology, Cornell University.

\section{Literature Cited}

Abrams, P. A. 2000. The evolution of predator-prey interactions: theory and evidence. Annual Review of Ecology and Systematics 31:79-105.

$\rightarrow$ Ardia, D. R., J. E. Gantz, B. C. Schneider, and S. Strebel. 2012. Costs of immunity in insects: an induced immune response increases metabolic rate and decreases antimicrobial activity. Functional Ecology 26:732-739.

Ayal, Y., and R. F. Green. 1993. Optimal egg distribution among host patches for parasitoids subject to attack by hyperparasitoids. American Naturalist 141:120-138.

Bernstein, C., and G. Driessen. 1996. Patch-marking and optimal search patterns in the parasitoid Venturia canescens. Journal of Animal Ecology 65:211-219.

Bouskila, A., I. C. Robertson, M. E. Robinson, B. D. Roitberg, B. Tenhumberg, A. J. Tyre, and E. van Randen. 1995. Submaximal oviposition rates in a mymarid parasitoid: choosiness should not be ignored. Ecology 76:1990-1993.

Briggs, C. J., and J. Latto. 1996. The window of vulnerability and its effect on relative parasitoid abundance. Ecological Entomology 21: 128-140.

Castelo, M. K., S. van Nouhuys, and J. C. Corley. 2010. Olfactory attraction of the larval parasitoid, Hyposoter horticola, to plants infested with eggs of the host butterfly, Melitaea cinxia. Journal of Insect Science 10:1-16.

Charnov, E. L. 1976. Optimal foraging, the marginal value theorem. Theoretical Population Biology 9:129-136. 
$\rightarrow$ Charnov, E. L., and S. W. Skinner. 1984. Evolution of host selection and clutch size in parasitoid wasps. Florida Entomologist 67:5-21

$\rightarrow$. 1985. Complementary approaches to understanding parasitoid oviposition decisions. Environmental Entomology 14:383391.

Costa, J. T. 2006. The other insect societies. Belknap Press of Harvard University Press, Cambridge, MA.

$\rightarrow$ Couchoux, C., and S. van Nouhuys. 2014. Effects of intraspecific competition and host-parasitoid developmental timing on foraging behaviour of a parasitoid wasp. Journal of Insect Behavior 27:283-301

$\rightarrow$ Cronin, J., and D. Strong. 1993a. Substantially submaximal oviposition rates by a mymarid egg parasitoid in the laboratory anc field. Ecology 74:1813-1825.

$\rightarrow-1993 b$. Superparasitism and mutual interference in the egg parasitoid Anagrus delicatus (Hymenoptera, Mymaridae). Eco logical Entomology 18:293-302.

$\rightarrow$ Driessen, G., and C. Bernstein. 1999. Patch departure mechanisms and optimal host exploitation in an insect parasitoid. Journal of Animal Ecology 68:445-459.

$\rightarrow$ Eliassen, S., C. Jorgensen, M. Mangel, and J. Giske. 2009. Quantifying the adaptive value of learning in foraging behavior. American Naturalist 174:478-489.

Friedlander, T. P. 1985. Egg mass design relative to surfaceparasitizing parasitoids, with notes on Asterocampa clyton (Lepi doptera: Nymphalidae). Journal of Research on the Lepidoptera 24:250-257.

$\rightarrow$ Gillespie, J. H. 1977. Natural selection for variances in offsprin numbers: a new evolutionary principle. American Naturalist 111: 1010-1014.

$\rightarrow$ Godfray, H., M. Hassell, and R. Holt. 1994. The population dynamic consequences of phenological asynchrony between parasitoid: and their hosts. Journal of Animal Ecology 63:1-10.

$\rightarrow$ Hanski, I. 2011. Eco-evolutionary spatial dynamics in the Glanville fritillary butterfly. Proceedings of the National Academy of Sciences of the USA 108:14397-14404.

$\rightarrow$ Hanski, I., and E. Meyke. 2005. Large-scale dynamics of the Glanville fritillary butterfly: landscape structure, population processes, and weather. Annales Zoologici Fennici 42:379-395.

Hardy, I. C. W., M. Goubault, and T. P. Batchelor. 2013. Hymenopteran contests and agonistic behaviour. Pages 147-177 in I. C. W Hardy, M. Goubault, and T. P. Batchelor, eds. Animal contests. Cambridge University Press, Cambridge.

$\rightarrow$ Hassell, M. P. 2000. Host-parasitoid population dynamics. Journal of Animal Ecology 69:543-566.

$\rightarrow$ Hoffmeister, T. S., and B. D. Roitberg. 1997. To mark the host or the patch: decisions of a parasitoid searching for concealed host larvae. Evolutionary Ecology 11:145-168.

$\rightarrow$ Höller, C., and R. Hörmann. 1993. Patch marking in the aphid hyperparasitoid, Dendrocerus carpenteri: the information contained in patch marks. Oecologia (Berlin) 94:128-134.

Hondo, M. T., T. Onodera, and N. Morimoto. 1995. Parasitoid attack on a pyramid shaped egg mass of the peacock butterfly Inachis io geisha (Lepidoptera: Nymphalidae). Applied Entomology and Zoology 30:271-276.

$\rightarrow$ Hopper, K. R. 1999. Risk-spreading and bet-hedging in insect population biology. Annual Review of Entomology 44:535-560.

$\rightarrow$ Jervis, M. A., G. E. Heimpel, P. N. Ferns, J. A. Harvey, and N. Kidd. 2001. Life-history strategies in parasitoid wasps: a comparativi analysis of “ovigeny.” Journal of Animal Ecology 70:442-458.
JMP. 2012. JMP PRO, 64-bit ed. SAS Institute, Cary, NC.

Kankare, M., S. van Nouhuys, O. Gaggiotti, and I. Hanski. 2005. Metapopulation genetic structure of two coexisting parasitoids of the Glanville fritillary butterfly. Oecologia (Berlin) 143:77-84.

$\rightarrow$ Kraaijeveld, A. R., J. Ferrari, and H. C. J. Godfray. 2002. Costs of resistance in insect-parasite and insect-parasitoid interactions. Parasitology 125:S71-S82.

Kuussaari, M. S., S. van Nouhuys, J. Hellmann, and M. C. Singer 2004. Larval biology of checkerspots. Pages 138-160 in M. Kuussaari, S. van Nouhuys, J. Hellmann, and M. C. Singer, eds. On the wings of checkerspots: a model system for population biology. Oxford University Press, Oxford.

$\rightarrow$ Lavine, M. D., and M. R. Strand. 2002. Insect hemocytes and their role in immunity. Insect Biochemistry and Molecular Biology 32:1295-1309.

Mangel, M. 1989. An evolutionary interpretation of the motivation to oviposit. Journal of Evolutionary Biology 2:157-172.

. 2006. The theoretical biologist's toolbox: quantitative methods for ecology and evolutionary biology. Cambridge University Press, Cambridge.

Montovan, K. J., C. Couchoux, L. E. Jones, H. K. Reeve, and S. van Nouhuys. 2014. Data from: The puzzle of partial resource use by a parasitoid wasp. American Naturalist, Dryad Digital Repository, http://dx.doi.org/10.5061/dryad.h08r6.

$\rightarrow$ Nakamichi, Y., Y. Toquenaga, and K. Fujii. 2008. Persistent hostparasitoid interaction caused by host maturation variability. Population Ecology 50:191-196.

Ojanen, S. P., M. Nieminen, E. Meyke, J. Pöyry, and I. Hanski. 2013. Long-term metapopulation study of the Glanville fritillary butterfly (Melitaea cinxia): survey methods, data management, and long-term population trends. Ecology and Evolution 3:3713-3737.

Rajon, E., E. Desouhant, M. Chevalier, F. Débias, and F. Menu. 2014. The evolution of bet hedging in response to local ecological conditions. American Naturalist 184:E1-E15.

R Development Core Team. 2011. R: a language and environment for statistical computing. R Foundation for Statistical Computing, Vienna.

Reichgelt, A. 2007. Density-dependent aggregation of hyperparasitoid Mesochorus stigmaticus. MS thesis. University of Helsinki, Helsinki.

Roitberg, B. D., and M. Mangel. 1988. On the evolutionary ecology of marking pheromones. Evolutionary Ecology 2:289-315.

$\rightarrow$ Rosenheim, J. A. 2011. Stochasticity in reproductive opportunity and the evolution of egg limitation in insects. Evolution 65:2300-2312.

$\rightarrow$ Rosenheim, J. A., and H. Mangel. 1994. Patch-leaving rules for parasitoids with imperfect host discrimination. Ecological Entomology 19:374-380.

$\rightarrow$ Saastamoinen, M. 2007. Life-history, genotypic, and environmental correlates of clutch size in the Glanville fritillary butterfly. Ecological Entomology 32:235-242.

$\rightarrow$ Schmid-Hempel, P. 2005. Evolutionary ecology of insect immune defenses. Annual Review of Entomology 50:529-551.

Shaw, M. R., C. Stefanescu, and S. van Nouhuys. 2009. Parasitoids of European butterflies. Pages 130-156 in J. Settele, T. G. Shreeve, M. Konvicka, and H. Van Dyck, eds. Ecology of butterflies in Europe. Cambridge University Press, Cambridge.

$\rightarrow$ Sih, A. 1980. Optimal foraging: partial consumption of prey. American Naturalist 116:281-289.

Slobodkin, L. B. 1974. Prudent predation does not require group selection. American Naturalist 108:665-678. 
$\rightarrow$ Smith, M. J. 1964. Group selection and kin selection. Natur $\rightarrow$ 201:1145-1147.

$\rightarrow$ Speirs, D. C., T. N. Herratt, and S. F. Hubbard. 1991. Parasitoid diets: does superparasitism pay? Trends in Ecology and Evolution 6:22-25

$\rightarrow$ Sullivan, D. J., and W. Völkl. 1999. Hyperparasitism: multitrophic ecology and behavior. Annual Review of Entomology 44:291-315

$\rightarrow$ van Alphen, J. J. M., and M. E. Visser. 1990. Superparasitism as an adaptive strategy for insect parasitoids. Annual Review of Ento mology 35:59-79.

$\rightarrow$ van Nouhuys, S., and J. Ehrnsten. 2004. Wasp behavior leads to uniform parasitism of a host available only a few hours per year Behavioral Ecology 15:661-665.

$\rightarrow$ van Nouhuys, S., and I. Hanski. 2002. Colonization rates and distances of a host butterfly and two specific parasitoids in a frag. mented landscape. Journal of Animal Ecology 71:639-650.

$\rightarrow$ van Nouhuys, S., and R. Kaartinen. 2008. A parasitoid wasp uses landmarks while monitoring potential resources. Proceedings of the Royal Society B: Biological Sciences 275:377-385.

$\rightarrow$ van Nouhuys, S., S. Niemikapee, and I. Hanski. 2012. Variation in a host-parasitoid interaction across independent populations. Insects 4:1236-1256

$\rightarrow$ van Nouhuys, S., and E. Punju. 2010. Coexistence of competing parasitoids: which is the fugitive and where does it hide? Oikos 119:61-70.
Associate Editor: Marc Mangel Editor: Troy Day

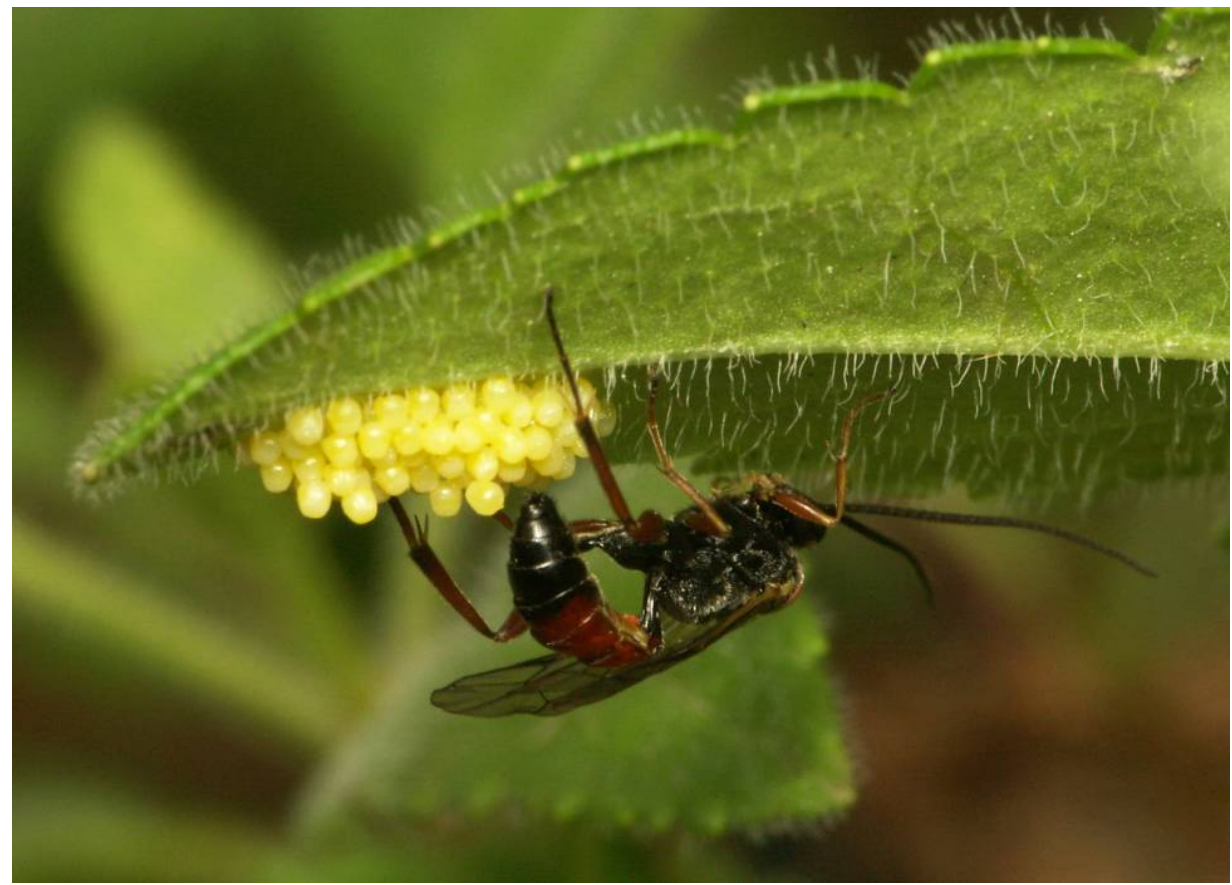

The parasitoid wasp Hyposoter horticola probing the egg cluster of its host butterfly, Melitaea cinxia, with its ovipositor. Photo by Saskya van Nouhuys. 